\title{
Double-stranded DNA breaks and gene functions in recombination and meiosis
}

\author{
Wuxing $\mathrm{Li}^{1}$, Hong $\mathrm{Ma}^{1}$ \\ ${ }^{I}$ The Department of Biology, The Intercollege Graduate Degree Program in Plant Physiology, The Huck Institutes of the Life Sciences, \\ The Pennsylvania State University, University Park, PA 16802, USA
}

Meiotic prophase I is a long and complex phase. Homologous recombination is an important process that occurs between homologous chromosomes during meiotic prophase I. Formation of chiasmata, which hold homologous chromosomes together until the metaphase I to anaphase I transition, is critical for proper chromosome segregation. Recent studies have suggested that the SPO11 proteins have conserved functions in a number of organisms in generating sites of double-stranded DNA breaks (DSBs) that are thought to be the starting points of homologous recombination. Processing of these sites of DSBs requires the function of RecA homologs, such as RAD51, DMC1, and others, as suggested by mutant studies; thus the failure to repair these meiotic DSBs results in abnormal chromosomal alternations, leading to disrupted meiosis. Recent discoveries on the functions of these RecA homologs have improved the understanding of the mechanisms underlying meiotic homologous recombination.

Cell Research (2006) 16:402-412. doi:10.1038/sj.cr.7310052; published online 15 May 2006

Keywords: meiosis, homologous recombination, double-stranded DNA breaks, SPO11, RAD51, DMC1

Meiosis is a highly coordinated cell division, which generates four haploid reproductive cells required for sexual reproduction. Meiosis involves one round of DNA replication and two nuclear divisions, meiosis I and meiosis II. The first nuclear division leads to the segregation of homologous chromosomes (homologs), and is unique to meiosis. During the second division, sister chromatids are separated, resulting in the formation of four haploid nuclei and followed by the meiotic cytokinesis that forms four haploid cells. Similar to mitosis, both meiosis I and meiosis II can be divided into four stages: prophase, metaphase, anaphase, and telophase.

However, meiosis I differs from meiosis II as meiosis I involves homology search, pairing, interhomolog recombination, and synapsis of homologs, processes that are required for correct association and segregation of homologs. The prophase stage of meiosis I, or prophase I, has been the target of interest because of the occurrence of these major

Correspondence: Hong Ma

Tel: 814-863-6414; Fax: 814-863-1357;

E-mail: hxm16@psu.edu processes of chromosome interactions. During early prophase I, arms of sister chromosomes are closely associated by protein complexes called cohesins, which are removed during the metaphase I/anaphase I transition. However, the centromere regions remained associated until the segregation of sister chromatids during meiosis II. Homologous pairing is the result of interaction between homologous chromosomes relying on the homology of DNA sequences $[1,2]$, and is considered to be a transient and non-stable association between homologous chromosomes. Pairing between homologous chromosomes facilitates the process of recombination. The recombination process confers the interexchange of genetic information between non-sister chromatids, and generates chiasmata, which ensure proper association between homologous chromosomes prior to chromosome segregation at anaphase I. Synapsis, however, is a stable association by forming synaptonemal complexes between chromosomes. Synaptonemal complexes are threepartite proteinacious complexes formed between homologs and are to be removed at the end of meiotic prophase I.

In this review, we will discuss the mechanisms underlying meiotic recombination, based on the results from recent molecular and genetic studies, focusing on the formation 
and processing of double-stranded DNA breaks (DSBs) as well as genes involved in these processes in various organisms. Recently identified plant genes that are involved in meiotic recombination will also be discussed.

\section{Meiotic recombination between homologous chro- mosomes}

Recombination refers to the exchange or transfer of DNA information between molecules [3]. Homologous recombination is a type of recombination based on the sequence homology between partners and is commonly formed in both mitotic and meiotic cells. Genetic and biochemical studies on recombination processes have generated a number of models, among which the double-stranded DNA break repair model (DSBR) is most supported (Figure 1).

The process of recombination is thought to occur at the sites of recombination nodules (RNs), which are small proteinacious structures associated with SCs. RNs were first identified under the electron microscopy in the female Drosophila [6]. Based on the timing of the appearance on meiotic chromosomes and other factors, including their

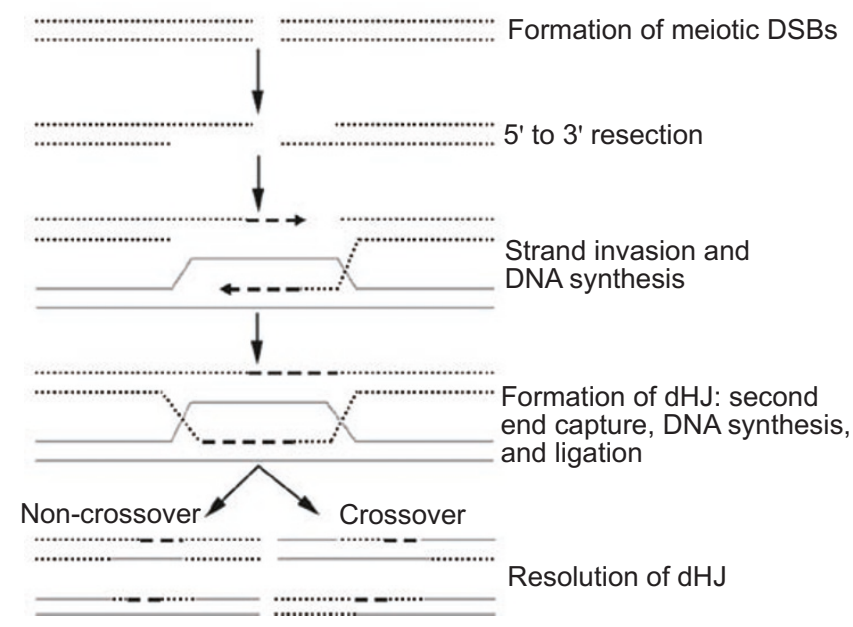

Figure 1 A diagram of the double-strand break repair (DSBR) model. According to this model, recombination is initiated by the generation of a double-stranded DNA break (DSB) on one of the recombining molecules, followed by the resection of the $5^{\prime}$ strand ends to generate two 3' single-stranded DNA overhangs. One of these 3 'overhangs, then invades the partner chromatid, and forms a D-loop. DNA synthesis from the $3^{\prime}$ ends using the partner as a template and subsequent ligation form a double Holliday junction $(\mathrm{dHJ})$. The pattern of resolution of this double-Holliday junction determines whether the recombination product is a crossover or a non-crossover [3-5]. The crossover corresponds to the chiasma, an important chromosome structure holding two homologs together from late prophase I to metaphase I- anaphase I transition. frequency, shape, size, and staining properties, RNs were empirically identified as two types: early RNs and late RNs $[7,8]$. Early RNs are abundant and they are associated with axial elements or SCs from leptotene to mid pachytene. From mid pachytene to late pachytene, late RNs appear on the central element of SCs. In most organisms, every pachytene chromosome has at least one late $\mathrm{RN}$, and in a number of organisms, the number and position of late RNs are correlated with crossover formation $[9,10]$. Since the RNs are correlated with sites of recombination and crossover formation, it is expected that the proteins involved in these processes are present in RNs. Indeed, RecA-like proteins have been found to be the components of early RNs in the lily plant [8], supporting the hypothesis that these RNs are sites of recombination.

\section{Genes involved in DSB formation: SPO11 and oth- ers}

The mechanisms for pairing can be divided into two groups: DSB-independent mechanisms and DSB-dependent mechanisms $[11,12]$. DSB-dependent mechanism involves the formation of DSBs and the interaction of DNA sequences for homology search. Recombination in budding yeast is initiated by the formation of DSBs, a process which may be highly conserved among other organisms [13, 14]. Depending on the size of genome, one meiotic nucleus may contain numerous DSBs [15] and recombinational repair of the DSBs occurs at the sites of initiation of synapsis, providing a way for pairing between homologous chromosomes $[2,16,17]$.

In budding yeast, the formation of DSBs requires a number of proteins (SPO11, RAD50, MRE11, XRS2, MER1, MER2, MEI4, MRE2, REC102, REC104, REC114) [18]. SPO11 catalyzes the formation of DSBs and is linked covalently to the 5 ends of unprocessed DSBs [19]. The SPO11 sequence suggests that it belongs to a novel family with similarity to the topo6 $\mathrm{A}$ gene product from the archaea $\mathrm{Sul}$ folobus shibatae [20]. In a topoisomerase-catalyzed cleavage reaction, a tyrosine residue attacks a phosphodiester bond, and generates DSBs via a transesterase mechanism with the assistance of a set of other gene products. This tyrosine residue is conserved in the SPO11 protein and is critical for its function [20]. Moreover, SPO11 homologs have been found in a wide range of organisms, including Arabidopsis thaliana, Caenorhabditis elegans, D. melanogaster, Coprinus cinereus, and mammals, indicating that this SPO11-catlayzed DSB generation is a conserved process among organisms [21-28]. Although the biochemical activity of SPO11 has not yet been determined, mutations in genes required for meiotic DSB repair result in chromosome fragmentation. However, this fragmentation can be 
eliminated in a spol1 background in different organisms, suggesting that SPO11 is responsible for generating DSBs during meiosis [29-35].

Furthermore, mutant studies have been performed with some of the identified SPO11 genes. In the budding yeast, loss of SPO11 function eliminates meiotic recombination and the formation of synaptonemal complexes but does not affect mitotic recombination and the mitotic cell cycle [36-38]. In addition, the spol1 mutant exhibits reduced condensation and pairing; however, there is still residual pairing, suggesting that either SPO11 is not essential in DSB-dependent pairing or there might be DSB-independent pairing mechanisms [39]. This is consistent with the report that somatic pairing has been found in the budding yeast $[39,40]$. A recent study assigns an early function of SPO11 in regulating meiotic S-phase progression, suggesting that SPO11 might be required for the formation of certain chromosome structures required for cell cycle progression [41]. In S. pombe, mutations in the SPO11 homolog rec12 cause reduced recombination, and rec12 may have additional functions after the completion of meiotic prophase I, as the Rec12 protein persists until anaphase II [42, 43]. Similarly, a mouse spoll mutant is infertile and mutant spermatocytes exhibit little or no synapsis [44]. Mutation in the Arabidopsis AtSPO11-1 gene shows abnormalities similar to those of the yeast spoll mutants, including greatly reduced recombination and synapsis. However, the presence of residual bivalents indicates that there might be SPO11-independent pairing, synapsis, and/or recombination mechanisms [45].

Therefore, spoll mutations in yeast and plants affect both recombination and synapsis, supporting the hypothesis that these two processes are closely associated in these organisms. However, in Drosophila and C. elegans spol1 mutants, although meiotic recombination is defective, formation of synaptonemal complexes were observed independent of SPO11 function [21, 22]. Interestingly, the Drosophila SPO11 homolog, MEI-W68, has a function in mitotic recombination. Careful phylogenetic analysis of known SPO11 proteins and other types of topoisomerases and functional analysis of SPO11 in other organisms would help to explain whether this is a new function for MEI-W68, or a function that appears to have been lost in yeast and plants.

Proteins other than SPO11 may also function in chromosome pairing and modeling to facilitate DSB formation, in regulating SPO11 activity, or in removing SPO11 from the sites after DSB formation [18]. In budding yeast RAD50, a large $153 \mathrm{kDa}$ protein with N-terminal ATP-binding domain exhibits ATP-dependent binding to double-stranded DNA, and is required for both meiotic recombination and synapsis $[46,47]$. It is also necessary for repairing mitotic
DSBs. RAD50 may serve in chromatin remodeling and is required for removing SPO11 from the $5^{\prime}$ end after DSB is made $[19,48,49]$. MRE11 and XRS2 function together with RAD50 as a complex [50-52]. This complex plays a role in a set of processes, including homologous recombination, non-homologous end joining, telomere maintenance, and removal of SPO11 from 5' end of newly formed DSBs [52-55].

In the Arabidopsis atrad50 mutant, chromosomes fail to synapse and the processing of meiotic DSBs is defective, resulting in the fragmentation of meiotic chromosomes that are visible starting at premetaphase I [56, 57]. Abnormalities in mitotic development is not obvious under normal growth conditions; however, mutant plants exhibit an increased sensitivity to the DNA-damaging agent methylmethane sulfonate [57]. An Arabidopsis atmre11 mutant meiocytes lack chromosome synapsis, and both mitotic and meiotic mutant cells contain AtSPO11-1-dependent chromosome fragments, suggesting that this gene functions downstream of AtSPO11-1; this is consistent with the function of RAD50-MRE11-XRS2 complex in budding yeast [35]. Moreover, the meiotic breaks in atmrell are not completely suppressed by atspo11-1 mutation, indicating that other pathways might be involved in generating DSBs.

\section{DSB processing and function of RecA proteins}

After the generation of DSBs by SPO11 and the resection of the DSBs by the complex of RAD50, MRE11, and XRS2 to produce 3' single-stranded DNA ends, the invasion of one of the 3' ssDNA ends is catalyzed by a group of proteins, including DMC1, RAD51, RAD52, RAD54, RAD55, RAD57, and TID1 [58, 59]. Among these proteins, DMC1 is a meiosis-specific protein. Phylogenetic analysis indicates that $\mathrm{DMC} 1$ is a RecA-like protein [60]. DMC1 homologs have been identified in a wide range of organisms, including budding and fission yeast, mammals, plants, and fungi [61-70]. In the budding yeast, the severity of $d m c 1$ mutants varies among different strains. The severe $d m c 1$ mutants of an SK1 strain show defective recombination, accumulation of unprocessed DSBs, and formation of abnormal SCs [71]. Mutations in the fission yeast $D M C 1$ cause reduced recombination [72]. Mouse mutants in DMC1 are both male and female sterile, with gametogenesis arrested at meiotic prophase I and meiotic chromosomes failing to synapse [73]. The Arabidopsis atdmc1 mutant fails to undergo meiotic synapsis; however, chromosomes remain intact [74]. Although normal $\mathrm{SC}$ is not formed, yeast and mouse $d m c 1$ mutants show signs of axial element formation, suggesting that $\mathrm{DMC} 1$ is required for the establishment of a connection linking two axial elements. 
In addition to DMC1, the budding yeast possesses another RecA homolog, RAD51. Different than DMC1, RAD51 functions in both meiotic and mitotic homologous recombinations [75]. In meiosis, rad51 mutants accumulate DSBs and exhibits reduced recombination [75]. The yeast RAD51 interacts directly with RAD54, a member of SWI2/MOT1 family [76]. Detailed analysis of the $d m c 1$ and rad51 mutants suggests that these two genes perform both overlapping and distinct functions in meiotic recombination [77]. Interestingly, these two proteins may share the same or similar recombination functions, because they can substitute each other under certain circumstances. Consistently, RAD51 may act in a complex with DMC1 and function in recombination as these proteins might form nuclear complexes prior to chromosome synapsis [78]. However, synapsis appears not to be severely affected in the rad51 and $d m c 1$ mutants, although the association of axial elements is substantially delayed [79], suggesting that the RAD51 and DMC1 may modulate synapsis or function later than the formation of synaptonemal complex.

RAD51 homologs have been isolated and characterized in a wide range of organisms [61, 70, 80-84]. The fission yeast $R A D 51$ homolog $R H P 51$ plays roles similar to those of the budding yeast $R A D 51$, with roles that are overlapping with and distinct from those of the fission yeast $D M C 1$ gene in DSBs repair and meiotic recombination $[72,81]$. The RAD51 homolog in Aspergillus nidulans shows a $67.4 \%$ sequence identity to budding yeast RAD51 [80]. While a deletion of two amino acid residues in the $A$. nidulans $R A D 51$ homolog $(u v s C)$ causes arrest at meiotic prophase I, a null mutation causes the failure of meiotic cells to enter meiosis, indicating that this gene has a function prior to entering meiosis [80]. In Drosophila females, RAD51 plays essential roles in repairing meiotic DSBs and also in meiotic chromosome pairing $[85,86]$. In C. elegans, rad51 RNAi lines show defective chromosome morphology at diakinesis and accumulation of meiotic DSBs in oocytes $[84,87]$. In addition, rad51 mutations in mice cause early embryo lethality, indicating that the mouse RAD51 gene has an essential function in mitotic development [88, 89]. In Arabidopsis, a null mutation in RAD51 causes defective meiotic recombination and synapsis, and an accumulation of unprocessed meiotic DSBs [33]. Different than the function of RAD51 in budding and fission yeast, RAD51 homologs in A. nidulans, Drosophila, C. elegans, and Arabidopsis seem to be dispensable for processing mitotic DSBs under normal growth conditions. Nevertheless, hypersensitivity to DNA damaging reagents have been revealed in these rad51 mutants, suggesting that there is a RAD51-dependent pathway active in response to an increased number of mitotic DSBs caused by damage.

Another protein, BRCA2, has recently been shown to be involved in the processing of meiotic DSBs, possibly by interacting with RAD51 and/or DMC1. In animals, BRCA2 has been demonstrated to function in maintaining genome stability and a mutation in mouse $B R C A 2$ results in early embryo lethality that might be caused by aberrant chromosome rearrangements and fragmentations [90, 91]. The brca 2 mutant of Ustilago and a partial brca 2 mutant of mouse exhibit disrupted meiosis, and the presence of abnormal chromosomal alterations indicates a role of $B R C A 2$ in maintaining genome stability in meiosis [92, 93]. Notably, it has been found that in animals, BRCA2 might be required for correct positioning of RAD51 foci in both mitotic and meiotic cells [91, 92], consistent with the similar abnormalities of the brca2 to the rad51 knockout mice. In Arabidopsis, silencing of the BRCA2 genes induces formation of fragmented chromosomes, possibly the consequence of failure to process meiotic DSBs [34]. In Ustilago, BRCA2 was found to interact with RAD51 [93]; similarly, the Arabidopsis BRCA2 interacts with RAD51 and DMC1 in yeast two-hybrid experiments [34], indicating the BRCA2 may have conserved functions in the processing of meiotic DSBs by properly loading RAD51 and DMC1 to the sites of breaks.

In addition to mutant studies, biochemical results including patterns of protein localization and interaction also suggest functions of RAD51 and DMC1 in chromosome paring, synapsis and recombination. Moreover, these studies together with the protein characterization results support the idea that these two proteins have both distinct and overlapping functions. RAD51 foci exhibit a change in numbers during meiotic prophase I, and studies suggest that these foci are correlated with the sites of DSBs and the formation of early RNs $[8,94]$. In the budding yeast, both proteins colocalize to meiotic chromosomes during meiotic prophase I and are thought to be components of early RNs [78]. In lily, however, although these two proteins colocalize on or adjacent to chromosomes from leptotene on to zygotene, the DMC1 foci disappear but the RAD51 foci retain at pachytene, indicating that RAD51 might have a late function after crossover formation [95]. Furthermore, in the budding yeast, normal loading of DMC1 onto chromosomes seems to be dependent on the presence of RAD51, as DMC1 foci are detectable but reduced in rad51 mutants, but RAD51 foci are normal in $d m c 1$ mutants [77, 78].

Although DMC1 and RAD51 proteins share a high degree of sequence similarity, recent studies suggest that their structural properties might be remarkably different. The human RAD51, like RecA protein in E. coli, forms typical helical nucleoprotein filaments that promote strand invasion and formation of heteroduplex DNA. However, the human DMC1, showing binding preference to ssDNA and promoting formation of strand exchange between 
homologous DNAs, forms octameric ring structures that may be stacked to form short filaments [96]. Further studies identified hydrogen bond interaction at the monomermonomer interfaces of DMC1 that is required for forming octamer ring structure [97]. In fission yeast, RAD51 also forms helical nucleoprotein filaments; however, different than that in human, fission yeast $\mathrm{DMC1}$ protein can form both helical filaments and stacked rings [98]. This study may stimulate further research in understanding the functions of DMC1 in fission yeast and its relationship to RAD51 function.

Biochemical studies indicate that both DMC1 and RAD51 exhibit DNA-stimulated ATPase activity, prefer to binding ssDNA, and catalyze ATP-dependent strand exchange reactions with homologous duplex DNA. However, double mutant studies of red 1 with $d m c 1$ and rad51 provide evidences supporting the conclusion that the functions of these two proteins are not identical [77]. RED1 is a phosphoprotein that serves as a structural component of axial element, and is important for synapsis and the establishment of an interhomolog-specific recombination pathway by promoting DSB formation [99-101]. Although both RAD51 and DMC1 function in promoting interhomolog recombination, in a red $1 \mathrm{dmcl}$ double mutant, interhomolog recombination is almost completely absent (Interhomolog: intersister $<0.1$, whereas a red rad51 double mutant has a reduced but relatively high level of residual interhomolog recombination (Interhomolog: intersister ratio is 0:35) [99]. Therefore, DMC1 may play a more critical role in directing the recombination into interhomolog pathway.

\section{RAD51 paralogs in animals and plants: RAD51B, RAD51C, RAD51D, XRCC2, and XRCC3}

In addition to $R A D 51$ and $D M C 1$, mammals possess other five RAD51 paralogs: RAD51B, RAD51C, RAD51D, $X R C C 2$, and $X R C C 3$ [102-106]. These genes exhibit various levels of sequence similarity to the RAD51 gene.

The human $R A D 51 B$ gene encodes a 305 amino-acid protein and is expressed widely, with the highest levels in tissues that are active in recombination [106]. Mutant analysis of $R A D 51 B$ in a chicken B lymphocyte DT40 cell line indicates that $R A D 51 B$ is important for maintaining genome integrity and for homologous recombinational repair [107, 108]. However, the rad51b mutant cell line is viable; although about $20 \%$ cells die after each division as a result of spontaneous chromosomal aberrations, indicating that $R A D 51 B$ is required for repairing DNA breaks or damages under normal growth conditions. Moreover, the rad51b cells exhibit increased sensitivity to DNA crosslinking agents. Interestingly, rad51b cells exhibit a reduction of damage-induced RAD51 foci formation, suggesting that RAD51B might function in proper loading of RAD51 upon DNA damages. Arabidopsis has a RAD51B homo$\log$, named AtRAD51B. The atrad51b mutant is fertile, undergoes normal meiosis, and normal vegetative growth under standard growth conditions $[109,110]$. The atrad51b mutant exhibits moderate sensitivity to DNA-damaging agents, including gamma-radiation and cisplatin, indicating that the function of $R A D 51 B$ is less important in plant mitosis, possibly because homologous recombination is less active in plants.

$R A D 51 C$ in human encodes a 376 AA protein showing $18-26 \%$ identity to other human RAD51 homologs [103]. The $R A D 51 C$ gene is expressed widely, with the highest level in the testis. Mutation in RAD51C results in DNA damage-sensitivity in a hamster cell line, and an increase in spontaneous chromosomal aberrations such as a lack of sister chromatid exchanges and increased isochromatid breaks [111, 112]. Moreover, mutant cell lines also exhibit reduced RAD51 foci formation upon DNA damage treatments, supporting the notion that RAD51C is a key component in RAD51-dependent processes. Drosophila possesses a $R A D 51 C$ homolog that encodes a 271 AA protein and mutation in this gene results in abnormal chromosomal behaviors, including a high percentage of oblong and fragmented chromosomes (77\%) [113]. However, Drosophila $R A D 51 C$ seems to be unnecessary for mitotic DNA repair or other mitotic processes as the mutant grows normally and does not show an increased sensitivity to either MMS or gamma rays. The authors proposed that because Drosophila lacks a detectable homolog of $D M C 1$, it is possible that Drosophila RAD51C and XRCC3 (see below) function together in a pathway specific for meiosis as a replacement of the DMC1 function. In Arabidopsis, which has a DMC1 homolog, RAD51C is critical in meiosis and a mutation in this gene causes striking fragmentation of meiotic chromosomes visible starting at the end of prophase I, suggesting that Arabidopsis RAD51C is critical for processing meiotic DNA breaks [31, 109]. Furthermore, homologous chromosomes in atrad51c fail to undergo synapsis and homolog juxtaposition [31].

RAD51D in mouse encodes a 319 AA protein with significant sequence similarity to other RAD51 proteins [105]. The mouse RAD51D gene is expressed widely and different sizes of transcripts are detected, suggesting the different mRNA splicing might be involved in regulating the $R A D 51 D$ function [105]. In human, the splicing variants of $R A D 51 D$ are also present, suggesting that this might be a conserved mechanism in mammals [114, 115]. Genetic studies suggest that $R A D 51 D$ also plays an important role in homologous recombination. In mouse, rad51d knockout mutants exhibit embryo lethality and fibroblast cell lines undergo cell lethality, suggesting that $R A D 51 D$ plays an im- 
portant role in cell proliferation [116]. In addition, rad51d mutant cells exhibit increased centrosome fragmentation and RAD51 foci formation [117]. Therefore, RAD51D may bind, possibly indirectly, to RAD51 and may be required for maintaining genome stability by repairing DNA damage, in conjunction with RAD51 [116]. The death of rad51d mouse embryo may also be a result of p53 activation, as a $p 53$ deletion extends the life span of rad51d embryos and rescues the cell lethality [117]. A recent study reports that RAD51D is also involved in telomere maintenance [118]. RAD51D is shown to localize to telomere regions in both mitotic and meiotic cells, and the mouse rad51d trp53 mutant exhibits telomeric DNA repeat shortening and increased telomere end-to-end joining. A RAD51D homolog has also been discovered in Arabidopsis; however, functional analysis has not yet been reported.

$\mathrm{X}$-ray repair complementing defective repair in Chinese hamster cells 2 (XRCC2) was identified in human cells based on isolating cDNA that can complement Xray-sensitive mutant cell lines. XRCC2 from human and mouse exhibits high similarity and in mouse, XRCC2 is expressed widely, with an elevated level in the testis [119]. The mutant cell line, irs 1 , shows extreme sensitivity to DNA cross-linking agents and genome instability [119, 120]. The mouse $X R C C 2$-deficient mutant exhibits embryo lethality and dies before or at birth. Embryonic cells exhibit genome instability as shown by the presence of high level of chromosomal aberrations and sensitivity to gamma rays. In irs 1 mutant cells, homologous recombinational repair of DNA DSBs is greatly reduced, although a normal level of non-homologous end-joining is present [121]. Therefore, $X R C C 2$ might play a critical role specific for homologous repair of mitotic DSBs [121, 122]. Detailed analysis of the human XRCC2 protein suggests that its putative ATPbinding domain is critical for its function in homologous recombination repair as site-specific mutations in the putative ATP-binding region fail to restore the irs 1 phenotype [123]. Similar to RAD51C and RAD51D, XRCC2 is also required for proper loading of RAD51 onto chromosomes as determined by the lack of RAD51 foci formation in irs 1 mutant cells [123].

Human $X R C C 3$ was isolated as a cDNA that partially restores MMC resistance to an irs $1 S F$ cell line [104]. irs $1 S F$ mutant cells exhibit reduced plating efficiency and growth rate, severe chromosome instability, and sensitivity to cisplatin and gamma rays. Further analysis using a novel fluorescence-based assay of the XRCC3-deficient irs 1 SF cell line revealed a 25 -fold reduction in homologous recombinational repair of DSBs, which suggests that $X R C C 3$ is involved in homologous recombination [124126]. In addition, RAD51 foci do not occur in the irs $1 S F$ mutant cells, indicating that a possible function of $X R C C 3$ in homologous recombinational repair is to establish or to stabilize the RAD51 foci upon DNA damages [127]. Transfection of the mutant cell line with the $X R C C 3$ cDNA increases the frequencies of homologous recombinational repair [125]. In addition to early function including initiation of homologous recombination, XRCC3 may also function at late stages in resolving HR intermediates [128]. In Arabidopsis, AtXRCC3 was identified as a homolog of mammalian XRCC3 [129]. AtXRCC3 is expressed widely but with the highest level in floral buds [129]. Mutation in AtXRCC 3 results in defective male and female meioses with severe fragmentation of meiotic chromosomes after pachytene [130]. This chromosome fragmentation can be largely suppressed by the atspo11-1 mutation, indicating that AtXRCC3 is required for repairing the meiotic DSBs generated by AtSPO11-1 [32]. Although the atxrcc 3 mutant plant has normal vegetative development, mutant cells and plants exhibit increased sensitivity to DNA-damaging treatments with MMC and bleomycin [130].

In mammals, biochemical analyses have shown that these mammalian RAD51 paralogs function in the form of complexes. Yeast two-hybrid tests confirmed that human RAD51D interacts with XRCC2 and RAD51C; in addition, yeast three-hybrid system indicates that a number of different pairs of interactions between these human RAD51 paralogs may occur simultaneously [131]. Later experiments with isotope-tagged proteins suggest that RAD51B is also involved in the above complex, making a four-component complex including RAD51B, RAD51C, RAD51D, and XRCC2 (defined as BCDX2) [132]. The BCDX2 complex binds to nicks of duplex DNA and exhibits ATPase activity in vitro. These results together with the observations that RAD51B [107, 108], RAD51C [111], RAD51D [117], and XRCC2 [123] are required for proper formation of RAD51 foci, indicate that these proteins may function as a complex both in assembling the RAD51 complex and in the initial processing of the single-stranded DNA at the damaged sites. Another complex, with RAD51C and XRCC3, was originally detected with a yeast two-hybrid system and then with interaction of proteins expressed in baculovirusinfected insect cells [132-134], and then confirmed with human cells lines that express isotope-tagged XRCC 3 or RAD51C proteins [135]. In addition, XRCC 3 is shown to be required for stabilizing RAD51C possibly by forming dimers, and this function requires the ATPase activity, suggesting that XRCC3 may regulate the dimerization through its ATP binding and hydrolysis activity [136]. Consistently, the $X R C C 3$ cDNA with a point mutation at a conservative amino acid of the ATPase domain fails to complement the irs $1 S F$ mutant cells, indicating that the ATPase activity is critical for the proper function of XRCC3 [136]. In Arabidopsis, yeast two-hybrid experiments have identified an 
interaction between AtXRCC3 and AtRAD51C [129] and an interaction between AtRAD51B and AtRAD51C [110], suggesting that the mammalian patterns of the RAD51 paralog functions via forming complexes are also present in plants.

\section{Other plant genes involved in meiotic recombina- tion}

In addition to studies using reverse genetics described above, plants also provide excellent systems in characterizing meiotic genes using forward genetics. In maize, this approach has identified a large number of mutants defective in meiosis [137], although mutated genes for most of them have not been isolated. Maize has served as an excellent model plant as it has a partially polyploidy genome, and some mutations allow pairing and synapsis between non-homologous chromosomes, possibly interfering with normal recombination between homologous chromosomes. Mutants defective in specifying homolog recognition include desynaptic1, desynaptic2, and phs1 [137-139]. In addition, it is notable that in phs 1 , the number of RAD51 foci on meiotic chromosomes is greatly reduced, although the RAD51 protein is present at normal level [139]. These results suggest that in addition to specifying paring and synapsis between homologous chromosomes, PHS1 may also function in the proper loading of RAD51 onto meiotic chromosomes. Furthermore, DSB can be formed and repaired in phs 1 even though this repair might be delayed, suggesting that maize may have a DSB-repairing system independent of RAD51.

In Arabidopsis, a mutant called solo dancers (sds) was isolated because of its greatly reduced fertility from a transposon insertional population [140]. The $s d s$ mutant exhibits a severe defect in homolog pairing, recombination, and bivalent formation. These phenotypes are very similar to those of atspo 11-1 and atdmc1 mutants, suggesting that SDS may be involved in the SPO11-dependent recombination pathway. $S D S$ is specifically expressed in male and female meiotic cells and encodes a putative novel cyclin $[140,141]$. Cyclins are known to regulate multiple processes during the mitotic cell cycle by activating cyclindependent kinases, suggesting that SDS may coordinate pairing, synapsis, and recombination by regulating protein activities via phosphorylation. In addition, proteolytic events might also be involved in the normal progression of meiotic recombination [142]. These results suggest that synapsis and recombination may be achieved by multiple pathways and be performed by multiple components. Further analysis of these and possibly additional mutants, the interplay between these genes, and the interplay between synapsis and recombination would help dissecting the mechanisms underlying associations between meiotic homologous chromosomes.

\section{Acknowledgements}

The authors thank Alexandra Surcel and Carey L Hendrix Lord for helpful comments on this manuscript. The work in our laboratory is supported by grants from the National Science Foundation (IBN-0077832, MCB9896340, MCB-0092075), the National Institutes of Health (RO1 GM63871), and the US Department of Agriculture (2001-35301-10570 and 2003-35301-13313). Wuxing L was partially supported by the Intercollege Graduate Degree Program in Plant Physiology. Hong M gratefully acknowledges the support of the John Simon Guggenheim Foundation and the National Institutes of Health (F33 GM72245-1).

\section{References}

1 Walker MY, Hawley RS. Hanging on to your homolog: the roles of pairing, synapsis and recombination in the maintenance of homolog adhesion. Chromosoma 2000; 109:3-9.

2 Tsubouchi H, Roeder GS. The importance of genetic recombination for fidelity of chromosome pairing in meiosis. Dev Cell 2003; 5:915-925.

3 Krogh BO, and Symington LS. Recombination proteins in yeast. Ann Rev Genet 2004; 38:233-271.

4 Haber JE, Ira G, Malkova A, et al. Repairing a double-strand chromosome break by homologous recombination: revisiting Robin Holliday's model. Phil Trans Royal Soc London Series B-Biol Sci 2004; 359:79-86.

5 Haber JE. Partners and pathways - repairing a double-strand break. Trends Genet 2000; 16:259-264.

6 Carpenter AT. Electron microscopy of meiosis in Drosophila melanogaster females: II. The recombination nodule — a recombination-associated structure at pachytene? Proc Natl Acad Sci USA 1975; 72:3186-3189.

7 Bojko M. Two kinds of "recombination nodules" in Neurospora crassa. Genome 1989; 32:309-317.

8 Anderson LK, Offenberg HH, Verkuijlen WMHC, et al. RecAlike proteins are components of early meiotic nodules in lily. Proc Natl Acad Sci USA 1997; 94:6868-6873.

9 Croft JA, Jones GH. Meiosis in Mesostoma ehrenbergii ehrenbergii. IV. Recombination nodules in spermatocytes and a test of the correspondence of late recombination nodules and chiasmata. Genetics 1989; 121:255-262.

10 Sherman JD, Stack SM. Two-dimensional spreads of synaptonemal complexes from solanaceous plants. VI. High-resolution recombination nodule map for tomato (Lycopersicon esculentum). Genetics 1995; 141:683-708.

11 Page SL, Hawley RS. Chromosome choreography: The meiotic ballet. Science 2003; 301:785-789.

12 Gerton JL, Hawley RS. Homologous chromosome interactions in meiosis: diversity amidst conservation. Nat Rev Genet 2005; 6:477-487

13 Sun H, Treco D, Schultes NP, et al. Double-strand breaks at 
an initiation site for meiotic gene conversion. Nature 1989; 338:87-90.

14 Cao L, Alani E, Kleckner N. A pathway for generation and processing of double-strand breaks during meiotic recombination in S. cerevisiae. Cell 1990; 61:1089-1101.

15 Baudat F, Nicolas A. Clustering of meiotic double-strand breaks on yeast chromosome III. Proc Natl Acad Sci USA 1997; 94:5213-5218.

16 Page S, Hawley RS. The genetics and molecular biology of the synaptonemal complex. Ann Rev Cell Dev Biol 2004; 20:525558.

17 Petukhova GV, Romanienko PJ, Camerini-Otero RD. The Hop2 protein has a direct role in promoting interhomolog interactions during mouse meiosis. Dev Cell 2003; 5:927-936.

18 Paques F, Haber JE. Multiple pathways of recombination induced by double-strand breaks in Saccharomyces cerevisiae. Microbiol Mol Biol Rev 1999; 63:349-404.

19 Keeney S, Giroux CN, Kleckner N. Meiosis-specific DNA double-strand breaks are catalyzed by Spo11, a member of a widely conserved protein family. Cell 1997; 88:375-384.

20 Bergerat A, deMassy B, Gadelle D, et al. An atypical topoisomerase II from archaea with implications for meiotic recombination. Nature 1997; 386:414-417.

21 Dernburg AF, McDonald K, Moulder G, et al. Meiotic recombination in C. elegans initiates by a conserved mechanism and is dispensable for homologous chromosome synapsis. Cell 1998; 94:387-398.

22 McKim KS, Hayashi-Hagihara A. mei-W68 in Drosophila melanogaster encodes a Spo11 homolog: evidence that the mechanism for initiating meiotic recombination is conserved. Genes Dev 1998; 12:2932-2942.

23 Celerin M, Merino ST, Stone JE, et al. Multiple roles of Spo11 in meiotic chromosome behavior. EMBO J 2000; 19:27392750.

24 Shannon M, Richardson L, Christian A, et al. Differential gene expression of mammalian SPO11/TOP6A homologs during meiosis. FEBS Lett 1999; 462:329-334.

25 Romanienko PJ, Camerini-Otero RD. Cloning, characterization, and localization of mouse and human SPO11. Genomics 1999; 61:156-169.

26 Keeney S, Baudat F, Angeles M, et al. A mouse homolog of the Saccharomyces cerevisiae meiotic recombination DNA transesterase Spo11. Genomics 1999; 61:170-182.

27 Hartung F, Puchta H. Molecular characterisation of two paralogous SPO11 homologues in Arabidopsis thaliana. Nucleic Acids Res 2000; 28:1548-1554.

28 Metzler-Guillemain C, de Massy B. Identification and characterization of an SPO11 homolog in the mouse. Chromosoma 2000; 109:133-138.

29 Cervantes MD, Farah JA, Smith GR. Meiotic DNA breaks associated with recombination in $S$. pombe. Mol Cell 2000; 5:883-888.

30 Zenvirth D, Simchen G. Meiotic double-strand breaks in Schizosaccharomyces pombe. Curr Genet 2000; 38:33-38.

31 Li W, Yang X, Lin Z, et al. The AtRAD51C gene is required for normal meiotic chromosome synapsis and double-stranded break repair in Arabidopsis. Plant Physiol 2005; 138:965976.

32 Bleuyard JY, Gallego ME, White CI. The atspol1-1 mutation rescues atxrcc 3 meiotic chromosome fragmentation. Plant Mol Biol 2004; 56:217-224.

33 Li W, Chen C, Markmann-Mulisch U, et al. The Arabidopsis AtRAD51 gene is dispensable for vegetative development but required for meiosis. Proc Natl Acad Sci USA 2004; 101:1059610601.

34 Siaud N, Dray E, Gy I, et al. Brca2 is involved in meiosis in Arabidopsis thaliana as suggested by its interaction with Dmc1. EMBO J 2004; 23:1392-1401.

35 Puizina J, Siroky J, Mokros P, et al. Mre11 deficiency in Arabidopsis is associated with chromosomal instability in somatic cells and Spo11-dependent genome fragmentation during meiosis. Plant Cell 2004; 16:1968-1978.

36 Klapholz S, Waddell CS, Esposito RE. The role of the SPO11 gene in meiotic recombination in yeast. Genetics 1985; 110:187-216.

37 Wagstaff JE, Klapholz S, Waddell CS, et al. Meiotic exchange within and between chromosomes requires a common Rec function in Saccharomyces cerevisiae. Mol Cell Biol 1985; 5:3532-3544.

38 Giroux CN, Dresser ME, Tiano HF. Genetic control of chromosome synapsis in yeast meiosis. Genome 1989; 31:88-94.

39 Loidl J, Klein F, Scherthan H. Homologous Pairing Is Reduced but Not Abolished in Asynaptic Mutants of Yeast. J Cell Biol 1994; 125:1191-1200.

40 Weiner BM, Kleckner N. Chromosome Pairing Via Multiple Interstitial Interactions before and During Meiosis in Yeast. Cell 1994; 77:977-991.

41 Cha RS, Weiner BM, Keeney S, et al. Progression of meiotic DNA replication is modulated by interchromosomal interaction proteins, negatively by Spo11 and positively by Rec8. Genes Dev 2000; 14:493-503.

42 Sharif WD, Glick GG, Davidson MK, et al. Distinct functions of S. pombe Rec12 (Spo11) protein and Rec12-dependent crossover recombination (chiasmata) in meiosis I; and a requirement for Rec12 in meiosis II. Cell Chromosome 2002; 1:1.

43 Dewall, KM, Davidson MK, Sharif WD, et al. A DNA binding motif of meiotic recombinase Rec12 (Spo11) defined by essential glycine-202, and persistence of Rec12 protein after completion of recombination. Gene 2005; 356:77-84

44 Romanienko PJ, Camerini-Otero RD. The mouse Spoll gene is required for meiotic chromosome synapsis. Mol Cell 2000; 6:975-987.

45 Grelon M, Vezon D, Gendrot G, et al. AtSPO11-1 is necessary for efficient meiotic recombination in plants. EMBO J 2001; 20:589-600.

46 Alani E, Padmore R, Kleckner N. Analysis of wild-type and rad50 mutants of yeast suggests an intimate relationship between meiotic chromosome synapsis and recombination. Cell 1990; 61:419-436.

47 Raymond WE, Kleckner N. RAD50 protein of S. cerevisiae exhibits ATP-dependent DNA binding. Nucleic Acids Res 1993; 21:3851-3856.

48 Liu J, Wu TC, Lichten M. The location and structure of doublestrand DNA breaks induced during yeast meiosis: evidence for a covalently linked DNA-protein intermediate. EMBO J 1995; 14:4599-4608.

49 Ohta K, Nicolas A, Furuse M, et al. Mutations in the MRE11, RAD50, XRS2, and MRE2 genes alter chromatin configuration 
at meiotic DNA double-stranded break sites in premeiotic and meiotic cells. Proc Natl Acad Sci USA 1998; 95:646-651.

50 Ogawa H, Johzuka K, Nakagawa T, et al. Functions of the yeast meiotic recombination genes, MRE11 and MRE2. Adv Biophys 1995; 31:67-76.

51 Usui T, Ohta T, Oshiumi $\mathrm{H}$, et al. Complex formation and functional versatility of Mre11 of budding yeast in recombination. Cell 1998; 95:705-716.

52 Chamankhah M, Xiao W. Formation of the yeast Mre11-Rad50Xrs2 complex is correlated with DNA repair and telomere maintenance. Nucleic Acids Res 1999; 27:2072-2079.

53 Trujillo KM, Yuan SSF, Lee EYHP, et al. Nuclease activities in a complex of human recombination and DNA repair factors Rad50, Mre11, and p95. J Biol Chem 1998; 273:2144721450.

54 Chamankhah M, Fontanie T, Xiao W. The Saccharomyces cerevisiae mre11(ts) allele confers a separation of DNA repair and telomere maintenance functions. Genetics 2000; 155:569576.

55 Tsukamoto Y, Mitsuoka C, Terasawa M, et al. Xrs2 regulates Mre11 translocation to the nucleus and plays a role in telomere elongation and meiotic recombination. Mol Biol Cell 2005; 16:597-608.

56 Bleuyard JY, Gallego ME, White CI. Meiotic defects in the Arabidopsis rad50 mutant point to conservation of the MRX complex function in early stages of meiotic recombination. Chromosoma 2004; 113:197-203.

57 Gallego ME, Jeanneau M, Granier F, et al. Disruption of the Arabidopsis RAD50 gene leads to plant sterility and MMS sensitivity. Plant J 2001; 25:31-41.

58 Bannister LA, Schimenti JC. Homologous recombinational repair proteins in mouse meiosis. Cytogenet Genome Res 2004; 107:191-200.

59 Aylon Y, Kupiec M. New insights into the mechanism of homologous recombination in yeast. Mutat Res 2004; 566:231248.

60 Petersen G, Seberg O. Molecular evolution and phylogenetic application of DMC1. Mol Phylogenet Evol 2002; 22:43-50.

61 Stassen NY, Logsdon JM, Vora GJ, et al. Isolation and characterization of Rad51 orthologs from Coprinus cinereus and Lycopersicon esculentum, and phylogenetic analysis of eukaryotic recA homologs. Curr Genet 1997; 31:144-157.

62 Klimyuk VI, Jones JDG. AtDMC1, the Arabidopsis homologue of the yeast $D M C 1$ gene: Characterization, transposon-induced allelic variation and meiosis-associated expression. Plant J 1997; 11:1-14.

63 Yoshida K, Kondoh G, Matsuda Y, et al. The mouse RecA-like gene $\mathrm{Dmcl}$ is required for homologous chromosome synapsis during meiosis. Mol Cell 1998; 1:707-718.

64 Nara T, Saka T, Sawado T, et al. Isolation of a LIM15/DMC1 homolog from the basidiomycete Coprinus cinereus and its expression in relation to meiotic chromosome pairing. Mol Gen Genet 1999; 262:781-789.

65 Ding ZJ, Wang T, Chong K, et al. Isolation and characterization of $O s D M C 1$, the rice homologue of the yeast $D M C 1$ gene essential for meiosis. Sexual Plant Reprod 2001; 13:285-288.

66 Gupta RC, Golub E, Bi B, et al. The synaptic activity of HsDmc1, a human recombination protein specific to meiosis. Proc Natl Acad Sci U S A 2001; 98:8433-8439.
67 Shimazu J, Matsukura C, Senda M, et al. Characterization of a DMC1 homologue, RiLIM15, in meiotic panicles, mitotic cultured cells and mature leaves of rice (Oryza sativa L.). Theor Appl Genet 2001; 102:1159-1163.

68 Kathiresan A, Khush GS, Bennett J. Two rice DMC1 genes are differentially expressed during meiosis and during haploid and diploid mitosis. Sexual Plant Reprod 2002; 14:257-267.

69 Lamers AE, Heiney JP, Ram JL. CDNA sequence analysis of proteins involved in reproduction and cell cycle of the zebra mussel, Dreissena polymorpha. Invertebrate Reprod Dev 2002; 41:41-52.

70 Doutriaux MP, Couteau F, Bergounioux C, et al. Isolation and characterisation of the RAD51 and DMC1 homologs from Arabidopsis thaliana. Mol Gen Genet1998; 257:283-291.

71 Bishop DK, Park D, Xu L, et al. DMC1: a meiosis-specific yeast homolog of $E$. coli recA required for recombination, synaptonemal complex formation, and cell cycle progression. Cell 1992; 69:439-456.

72 Fukushima K, Tanaka Y, Nabeshima K, et al. Dmc1 of Schizosaccharomyces pombe plays a role in meiotic recombination. Nucleic Acids Res 2000; 28:2709-2716.

73 Pittman DL, Cobb J, Schimenti KJ, et al. Meiotic prophase arrest with failure of chromosome synapsis in mice deficient for Dmc1, a germline-specific RecA homolog. Mol Cell 1998; 1:697-705

74 Couteau F, Belzile F, Horlow C, et al. Random chromosome segregation without meiotic arrest in both male and female meiocytes of a dmc1 mutant of Arabidopsis. Plant Cell 1999; 11:1623-1634.

75 Shinohara A, Ogawa H, Ogawa T. Rad51 protein involved in repair and recombination in $S$. cerevisiae is a RecA-like protein. Cell 1992; 69:457-470.

76 Jiang H, Xie Y, Houston P, et al. Direct association between the yeast Rad51 and Rad54 recombination proteins. J Biol Chem 1996; 271:33181-33186.

77 Shinohara A, Gasior S, Ogawa T, et al. Saccharomyces cerevisiae recA homologues RAD51 and DMC1 have both distinct and overlapping roles in meiotic recombination. Genes Cells 1997; 2:615-629.

78 Bishop DK. RecA homologs Dmc1 and Rad51 interact to form multiple nuclear complexes prior to meiotic chromosome synapsis. Cell 1994; 79:1081-1092.

79 Rockmill B, Sym M, Scherthan H, et al. Roles for two RecA homologs in promoting meiotic chromosome synapsis. Genes Dev 1995; 9:2684-2695.

80 vanHeemst D, Swart K, Holub EF, et al. Cloning, sequencing, disruption and phenotypic analysis of $u v s C$, an Aspergillus nidulans homologue of yeast RAD51. Mol Gen Genet 1997 254:654-664.

81 Muris DFR, Vreeken K, Schmidt H, et al. Homologous recombination in the fission yeast Schizosaccharomyces pombe: Different requirements for the $\operatorname{rhp} 51(+), \operatorname{rhp} 54(+)$ and $\operatorname{rad} 22(+)$ genes. Curr Genet 1997; 31:248-254.

82 Hayashi I, Morikawa K, Ishino Y. Specific interaction between DNA polymerase II (PolD) and RadB, a Rad51/Dmc1 homolog, in Pyrococcus furiosus. Nucleic Acids Res 1999; 27:46954702.

83 Ayora S, Piruat JI, Luna R, et al. Characterization of two highly similar Rad51 homologs of Physcomitrella patens. J Mol Biol 
2002; 316:35-49.

84 Rinaldo C, Bazzicalupo P, Ederle S, et al. Roles for Caenorhabditis elegans Rad51 in meiosis and in resistance to ionizing radiation during development. Genetics 2002; 160:471-479.

85 Yoo S, McKee BD. Functional analysis of the Drosophila Rad5l gene $(\operatorname{spn} A)$ in repair of DNA damage and meiotic chromosome segregation. DNA Repair 2005; 4:231-242.

86 Staeva-Vieira E, Yoo S, Lehmann R. An essential role of DmRad51/SpnA in DNA repair and meiotic checkpoint control. EMBO J 2003; 22:5863-5874.

87 Takanami T, Mori A, Takahashi H, et al. Caenorhabditis elegans Ce-rdh-1/Rad51 functions after double-strand break formation of meiotic recombination. Chromosome Res 2003; 11:125-135.

88 Lim DS, Hasty P. A mutation in mouse rad51 results in an early embryonic lethal that is suppressed by a mutation in $\mathrm{p} 53$. Mol Cell Biol 1996; 16:7133-7143.

89 Tsuzuki T, Fujii Y, Sakumi K, et al. Targeted disruption of the Rad51 gene leads to lethality in embryonic mice. Proc Natl Acad Sci USA 1996; 93:6236-6240.

90 Sharan SK, Morimatsu M, Albrecht U, et al. Embryonic lethality and radiation hypersensitivity mediated by Rad51 in mice lacking Brca2. Nature 1997; 386:804-810.

$91 \mathrm{Yu}$ VP, Koehler M, Steinlein C, et al. Gross chromosomal rearrangements and genetic exchange between nonhomologous chromosomes following BRCA2 inactivation. Genes Dev 2000; 14:1400-1406.

92 Sharan SK, Pyle A, Coppola V, et al. BRCA2 deficiency in mice leads to meiotic impairment and infertility. Development 2004; 131:131-142.

93 Kojic M, Kostrub CF, Buchman AR, et al. BRCA2 homolog required for proficiency in DNA repair, recombination, and genome stability in Ustilago maydis. Mol Cell 2002; 10:683691.

94 Moens PB, Chen DJ, Shen ZY, et al. Rad51 immunocytology in rat and mouse spermatocytes and oocytes. Chromosoma 1997; 106:207-215.

95 Ikeya T, Shinohara A, Sato S, et al. Localization of mouse Rad51 and Lim15 proteins on meiotic chromosomes at late stages of prophase 1. Genes Cells 1996; 1:379-389.

96 Passy SI, Yu X, Li ZF, et al. Human Dmc1 protein binds DNA as an octameric ring. Proc Natl Acad Sci USA 1999; 96:1068410688.

97 Kinebuchi T, Kagawa W, Enomoto R, et al. Structural basis for octameric ring formation and DNA interaction of the human homologous-pairing protein Dmc1. Mol Cell 2004; 14:363374.

98 Sauvageau S, Stasiak AZ, Banville I, et al. Fission yeast Rad51 and Dmc1, two efficient DNA recombinases forming helical nucleoprotein filaments. Mol Cell Biol 2005; 25:4377-4387.

99 Schwacha A, Kleckner N. Interhomolog bias during meiotic recombination: Meiotic functions promote a highly differentiated interhomolog-only pathway. Cell 1997; 90:1123-1135.

100 Hollingsworth NM, Ponte L. Genetic interactions between HOP1, RED1 and MEK1 suggest that MEK1 regulates assembly of axial element components during meiosis in the yeast Saccharomyces cerevisiae. Genetics 1997; 147:33-42.

101 Smith AV, Roeder GS. The yeast Red1 protein localizes to the cores of meiotic chromosomes. J Cell Biol 1997; 136:957-
967.

102 Liu N, Lamerdin JE, Tebbs RS, et al. XRCC2 and XRCC3, new human Rad51-family members, promote chromosome stability and protect against DNA cross-links and other damages. Mol Cell 1998; 1:783-793.

103 Dosanjh MK, Collins DW, et al. Isolation and characterization of $R A D 51 C$, a new human member of the RAD51 family of related genes. Nucleic Acids Res 1998; 26:1179-1184.

104 Tebbs RS, Zhao Y, Tucker JD, et al. Correction of chromosomal instability and sensitivity to diverse mutagens by a cloned cDNA of the Xrcc3 DNA-repair gene. Proc Natl Acad Sci U S A 1995; 92:6354-6358.

105 Pittman DL, Weinberg LR, Schimenti JC. Identification, characterization and genetic mapping of Rad51d, a new mouse and human RAD51/RecA-related gene. Genomics 1998; 49:103111

106 Albala JS, Thelen MP, Prange C, et al. Identification of a novel human RAD51 homolog, RAD51B. Genomics 1997; 46:476479.

107 Takata M, Sasaki MS, Sonoda E, et al. The Rad51 paralog Rad51B promotes homologous recombinational repair. Mol Cell Biol 2000; 20:6476-6482.

108 Takata M, Sasaki MS, Tachiiri S, et al. Chromosome instability and defective recombinational repair in knockout mutants of the five Rad51 paralogs. Mol Cell Biol 2001; 21:2858-2866.

109 Bleuyard JY, Gallego ME, Savigny F, et al. Differing requirements for the Arabidopsis Rad51 paralogs in meiosis and DNA repair. Plant J 2005; 41:533-545.

110 Osakabe K, Abe K, Yamanouchi H, et al. Arabidopsis Rad51B is important for double-strand DNA breaks repair in somatic cells. Plant Mol Biol 2005; 57:819-833.

111 French CA, Masson JY, Griffin CS, et al. Role of mammalian RAD51L2 (RAD51C) in recombination and genetic stability. J Biol Chem 2002; 277:19322-19330.

112 Godthelp BC, Wiegant WW, van Duijn-Goedhart A, et al. Mammalian Rad51C contributes to DNA cross-link resistance, sister chromatid cohesion and genomic stability. Nucleic Acids Res 2002; 30:2172-2182.

113 Abdu U, Gonzalez-Reyes A, Ghabrial A, et al. The Drosophila $s p n D$ gene encodes a RAD51C-like protein that is required exclusively during meiosis. Genetics 2003; 165:197-204.

114 Kawabata M, Saeki K. Multiple alternative transcripts of the human homologue of the mouse TRAD/R51H3/RAD51D gene, a member of the recA/RAD51 gene family. Biochem Biophys Res Commun 1999; 257:156-162.

115 Kawabata M, Akiyama K, Kawabata T. Genomic structure and multiple alternative transcripts of the mouse TRAD/ RAD51L3/RAD51D gene, a member of the recA/RAD51 gene family. Biochim Biophys Acta-Gene Struct Expression 2004; 1679:107-116.

116 Pittman DL, Schimenti JC. Midgestation lethality in mice deficient for the RecA-related gene, Rad51d/Rad5113. Genesis 2000; 26:167-173.

117 Smiraldo PG, Gruver AM, Osborn JC, et al. Extensive chromosomal instability in Rad51d-deficient mouse cells. Cancer Res 2005; 65:2089-2096.

118 Tarsounas M, Munoz P, Claas A, et al. Telomere maintenance requires the RAD51D recombination/repair protein. Cell 2004; 117:337-347. 
119 Cartwright R, Tambini CE, Simpson PJ, et al. The XRCC2 DNA repair gene from human and mouse encodes a novel member of the recA/RAD51 family. Nucleic Acids Res 1998; 26:3084-3089.

120 Tambini CE, George AM, Rommens JM, et al. The XRCC2 DNA repair gene: Identification of a positional candidate. Genomics 1997; 41:84-92.

121 Johnson RD, Liu N, Jasin M. Mammalian XRCC2 promotes the repair of DNA double-strand breaks by homologous recombination. Nature 1999; 401:397-399.

122 Deans B, Griffin CS, Maconochie M, et al. Xrcc2 is required for genetic stability, embryonic neurogenesis and viability in mice. EMBO J 2000; 19:6675-6685.

123 O'Regan P, Wilson C, Townsend S, et al. XRCC2 is a nuclear RAD51-like protein required for damage-dependent RAD51 focus formation without the need for ATP binding. J Biol Chem 2001; 276:22148-22153.

124 Pierce AJ, Johnson RD, Thompson LH, et al. XRCC3 promotes homology-directed repair of DNA damage in mammalian cells. Genes Dev 1999; 13:2633-2638.

125 Brenneman MA, Weiss AE, Nickoloff JA, et al. XRCC3 is required for efficient repair of chromosome breaks by homologous recombination. Mut Res-DNA Repair 2000; 459:89-97.

126 Johnson RD, Jasin M. Double-strand-break-induced homologous recombination in mammalian cells. Biochem Soc Trans 2001; 29:196-201.

127 Bishop DK, Ear U, Bhattacharyya A, et al. Xrcc3 is required for assembly of Rad51 complexes in vivo. J Biol Chem 1998; 273:21482-21488.

128 Brenneman MA, Wagener BM, Miller CA, et al. XRCC3 controls the fidelity of homologous recombination: Roles for XRCC3 in late stages of recombination. Mol Cell 2002; 10:387395.

129 Osakabe K, Yoshioka T, Ichikawa H, et al. Molecular cloning and characterization of RAD51-like genes from Arabidopsis thaliana. Plant Mol Biol 2002; 50:71-81.

130 Bleuyard JY, White CI. The Arabidopsis homologue of Xrcc3 plays an essential role in meiosis. EMBO J 2004; 23:439449.

131 Schild D, Lio YC, Collins DW, et al. Evidence for simultaneous protein interactions between human Rad51 paralogs. J Biol Chem 2000; 275:16443-9.
132 Masson JY, Tarsounas MC, Stasiak AZ, et al. Identification and purification of two distinct complexes containing the five RAD51 paralogs. Genes Dev 2001; 15:3296-3307.

133 Masson JY, Stasiak AZ, Stasiak A, et al. Benson, F.E., and West, S.C. (2001). Complex formation by the human RAD51C and XRCC3 recombination repair proteins. Proc Natl Acad Sci USA 2001; 98:8440-8446.

134 Kurumizaka H, Ikawa S, Nakada M, et al. Homologous-pairing activity of the human DNA-repair proteins Xrcc3 center dot Rad51C. Proc Natl Acad Sci USA 2001; 98:5538-5543.

135 Wiese C, Collins DW, Albala JS, et al. Interactions involving the Rad51 paralogs Rad51C and XRCC3 in human cells. Nucleic Acids Res 2002; 30:1001-1008.

136 Yamada NA, Hinz JM, Kopf VL, et al. XRCC3 ATPase activity is required for normal XRCC3-Rad51C complex dynamics and homologous recombination. J Biol Chem 2004; 279:2325023254.

137 Golubovskaya IN, Grebennikova ZK, Auger DL, et al. The maize desynaptic1 mutation disrupts meiotic chromosome synapsis. Dev Genet 1997; 21:146-159.

138 Franklin AE, Golubovskaya IN, Bass HW, et al. Improper chromosome synapsis is associated with elongated RAD51 structures in the maize desynaptic2 mutant. Chromosoma 2003; 112:17-25

139 Pawlowski WP, Golubovskaya IN, Timofejeva L, et al. Coordination of meiotic recombination, pairing, and synapsis by PHS1. Science 2004; 303:89-92.

140 Azumi Y, Liu D, Zhao D, et al. Homolog interaction during meiotic prophase I in Arabidopsis requires the SOLO DANC$E R S$ gene encoding a novel cyclin-like protein. EMBO J 2002; 21:3081-3095.

141 Wang G, Kong H, Sun Y, et al. Genome-wide analysis of the cyclin family in Arabidopsis and comparative phylogenetic analysis of plant cyclin-like proteins. Plant Physiol 2004; 135:1084-1099.

142 Sanchez-Moran E, Jones GH, Franklin FC, et al. A puromycinsensitive aminopeptidase is essential for meiosis in Arabidopsis thaliana. Plant Cell 2004; 16:2895-2909.

Edited by Hong Wei Xue 